\title{
Sialidase NEU1 suppresses progression of human bladder cancer cells by inhibiting fibronectin-integrin a $5 \beta 1$ interaction and Akt signaling pathway
}

Xiaoman Zhou', Yanhong Zhai ${ }^{1}$, Changmei Liu', Ganglong Yang ${ }^{1}$, Jia Guo ${ }^{1}$, Guang Li ${ }^{2}$, Chengwen Sun ${ }^{2}$, Xiaowei $\mathrm{Qi}^{3}$, Xiang $\mathrm{Li}^{4}$ and Feng Guan ${ }^{1,4^{*}}$ (D)

\begin{abstract}
Background: Sialic acids are widely distributed in animal tissues, and aberrantly expressed in a variety of cancer types. High expression of sialic acid contributes to tumor aggressiveness by promoting cell proliferation, migration, angiogenesis, and metastasis. Sialidases are responsible for removal of sialic acids from glycoproteins and glycolipids.

Methods: N-glycomics of bladder cancer cells were detected by MALDI-TOF mass spectrometry. Sialic acid modification in bladder cancer tissue was determined by lectin blot. The down-regulation of NEU1 in bladder cancer cells was determined by high resolution liquid chromatography mass spectrometry (HR LC-MS). The effects of sialidase NEU1 expression on proliferation and apoptosis of human bladder cancer cells were examined by western blot, RT-PCR, confocal imaging and flow cytometry. Moreover, the function of sialic acids on fibronectinintegrin a5 $\beta 1$ interaction were assayed by immunoprecipitation and ELISA. The importance of NEU1 in tumor formation in vivo was performed using BALB/C-nu mice. Expression of NEU1 in primary human bladder cancer tissue samples was estimated using bladder cancer tissue microarray.

Results: (1) Downregulation of NEU1 was primarily responsible for aberrant expression of sialic acids in bladder cancer cells. (2) Decreased NEU1 expression was correlated with bladder cancer progression. (3) NEU1 overexpression enhanced apoptosis and reduced proliferation of bladder cancer cells. (4) NEU1 disrupted FNintegrin a5 31 interaction and deactivated the Akt signaling pathway. (5) NEU1 significantly suppressed in vivo tumor formation in BALB/c-nu mice.

Conclusions: Our data showed that NEU1 inhibited cancer cell proliferation, induced apoptosis, and suppressed tumor formation both in vitro and in vivo, by disrupting interaction of FN and integrin $\beta 1$ and inhibiting the Akt signaling pathway. Our observations indicate that NEU1 is an important modulator of the malignant properties of bladder cancer cells, and is a potential therapeutic target for prognosis and treatment of bladder cancer.
\end{abstract}

Keywords: Sialic acids, Sialidase, Apoptosis, Fibronectin, Integrin

\footnotetext{
* Correspondence: guanfeng@nwu.edu.cn

${ }^{1}$ The Key Laboratory of Carbohydrate Chemistry and Biotechnology, Ministry

of Education, School of Biotechnology, Jiangnan University, Wuxi, China

${ }^{4}$ Provincial Key Laboratory of Biotechnology, Joint International Research

Laboratory of Glycobiology and Medicinal Chemistry, College of Life Science,

Northwest University, Xi'an, China

Full list of author information is available at the end of the article
}

(c) The Author(s). 2020 Open Access This article is distributed under the terms of the Creative Commons Attribution 4.0 International License (http://creativecommons.org/licenses/by/4.0/), which permits unrestricted use, distribution, and reproduction in any medium, provided you give appropriate credit to the original author(s) and the source, provide a link to the Creative Commons license, and indicate if changes were made. The Creative Commons Public Domain Dedication waiver (http://creativecommons.org/publicdomain/zero/1.0/) applies to the data made available in this article, unless otherwise stated. 


\section{Background}

Sialic acid, a monosaccharide with a nine-carbon backbone, is often the terminal group on carbohydrate chains of glycoproteins and glycolipids [1, 2]. Sialic acids are widely distributed in animal tissues. $\mathrm{N}$-acetylneuraminic acid (Neu5Ac) and N-glycolylneuraminic acid (Neu5Gc) are the two major sialic acids in mammals [3]. Because of their negative electric charge, sialic acids play crucial roles in a variety of cellular functions, e.g., cell-cell interaction, determining conformation of glycoproteins on cell membranes, and masking antigenic determinants on receptor molecules [4-11].

Epithelial-mesenchymal transition (EMT) is a biological conversion process of polarized epithelial cells to mesenchymal phenotype, characterized by loss of cell-cell adhesion and epithelial polarity as well as the acquisition of migratory and invasive properties. EMT is regulated by multiple signaling networks, including extracellular signalregulated protein kinases (ERKs), mitogen-activated protein kinase (MAPK), phosphatidylinositol 3-kinase (PI3K)/ Akt, Smads, RhoB, $\beta$-catenin and c-fos [12-15]. Other than these signaling factors, aberrant expression and high sensitivity of sialic acid as a tumor marker have been reported in a variety of cancerous conditions, and in many EMT models [16-18]. High expression of sialic acid contributes to tumor aggressiveness by promoting cell proliferation, migration, angiogenesis, and metastasis. Twenty known sialyltransferases are responsible for addition of sialic acid to glycoproteins or glycolipids [19]. Dysregulated expression of certain sialyltransferases has been correlated with abnormal sialylation in cancer cells [20]. For example, overexpression of $\beta$-galactoside $\alpha$-2,6-sialyltransferase 1 (ST6GAL1) and $\alpha$-2,8-sialyltransferase 2 (ST 8SIA2) was associated with enhanced invasive phenotype and chemosensitivity of human hepatocellular carcinoma cells [21]. ST6GAL1 promotes transforming growth factor $\beta$ (TGF $\beta$ )-dependent EMT, and also maintenance of malignant phenotype of human carcinomas through a non-Smad signaling pathway [22]. Poly sialic acid, whose production is catalyzed by polysialyltransferases ST8SIA2 and ST8SIA4, shows high aberrant expression on a variety of tumors [23].

Dysregulated expression of sialidases (also known as neuraminidases) has been observed in many types of cancer. Four mammalian sialidases (termed NEU1, - 2, $-3,-4$ ) have been identified to date. Each has a distinct cellular location: NEU1 in lysosomes, NEU2 in cytoplasm, NEU3 in plasma membrane, and NEU4 in mitochondria [17]. Sialidase expression and function are frequent topics in cancer research. Upregulation of NEU3 expression has been reported in colon cancer [24] and renal cell carcinoma [25]. Inhibition of NEU3 expression resulted in accumulation of ganglioside GM3 in HeLa and A549 cells, leading to reduction of epidermal growth factor receptor (EGFR)/ ERK signaling and consequent reduction of cell growth [26]. NEU1 played a crucial role in regulation of integrin $\beta 4$-mediated signaling through desialylation of integrin $\beta 4$, and suppressed metastasis of human colon cancer cells [27]. In human lung microvascular endothelia, NEU1 inhibited in vitro angiogenesis through desialylation of adhesion molecule CD31 [28].

Bladder cancer is a common malignancy, affecting approximately 549,393 adults and leading cause of death about 199,922 patients worldwide in 2018 [29-31]. Our previous report described global quantitative glycomics analysis of human cell lines HCV29 (normal bladder epithelia), KK47 (benign non-muscle-invasive bladder cancer), and YTS-1 (highly malignant invasive bladder cancer) using lectin microarray and mass spectrometry (MS) methods [32]. We observed the carbohydrate antigen sialyl Lewis $\mathrm{X}\left(\mathrm{sLe}^{\mathrm{x}}\right)$, which is associated with tumor formation and metastasis, was significantly upregulated in bladder cancer cells, suggesting that bladder cancer formation may involve aberrant expression of sialylation.

We now describe (i) analysis of the expression of sialylated glycans and sialidases in bladder cancer cells in comparison to normal bladder epithelial cells, using quantitative glycomics analysis and SILAC (stable isotope labeling by amino acids in cell culture) technique, (ii) evaluation of aberrant NEU1 expression and its functional role in apoptosis and proliferation of bladder cancer cells, and (iii) suppression of human bladder cancer by NEU1 in vitro and in vivo.

\section{Methods}

\section{Cell lines and cell culture}

Human cell lines HCV29 (normal bladder mucosal epithelia), KK47 (benign non-muscle-invasive bladder cancer), and YTS-1 (highly malignant invasive bladder cancer) were kindly provided by Dr. S. Hakomori (The Biomembrane Institute, Seattle, WA, USA) [33]. Human uroepithelial cell line SV-HUC-1, transitional carcinoma cell lines T24 and J82 were from the Cell Bank of the Chinese Academy of Sciences (Shanghai). Cells were cultured as described in Supplementary In formation/Methods.

\section{Determination of sialidase activity}

Sialidase activity was determined using 2 '-(4-methylumbelliferyl) $-\alpha-\mathrm{D}-\mathrm{N}$-acetylneuraminic acid sodium (4-MUNANA) (Sigma-Aldrich) as substrate [34]. Fluorescence intensity was measured by spectrofluorometer (Synergy H4 Hybrid Multi-Mode Microplate Reader, BioTek; Winooski, VT, USA) with excitation wavelength $365 \mathrm{~nm}$ and emission wavelength $450 \mathrm{~nm}$. 
Derivatization of released $\mathrm{N}$-linked glycans with $\left[{ }^{12} \mathrm{C}_{6}\right]-$ or $\left[{ }^{13} \mathrm{C}_{6}\right]$-aniline

Ten $\mu \mathrm{L}\left[{ }^{12} \mathrm{C}_{6}\right]$ - or $\left[{ }^{13} \mathrm{C}_{6}\right]$-aniline (Sigma-Aldrich) and $25 \mu \mathrm{L}$ fresh $\mathrm{NaCNBH}_{3}(1 \mathrm{M})$ prepared in DMSO/ acetic acid $(7: 3, v / v)$ were added separately to amidated N-linked glycans from KK47 and HCV29 cells, and incubated at $75^{\circ} \mathrm{C}$ for $10 \mathrm{~min}$ as described previously [32, 35]. The mixture was lyophilized under vacuum, redissolved in $500 \mu \mathrm{L}$ 1-butanol/ methanol/ $\mathrm{H}_{2} \mathrm{O}$ (BMW), and desalted with Sepharose 4B. Eluted glycan derivatives were dried and stored in the dark at $-20^{\circ} \mathrm{C}$.

\section{MS analysis of sialylated $\mathrm{N}$-glycan profiles}

$\mathrm{N}$-glycans were characterized by MALDI-TOF/TOF-MS (UltrafleXtreme, Bruker Daltonics; Bremen, Germany) as described previously [32]. Representative MS spectra of $\mathrm{N}$-glycans with signal-to-noise ratios $>3$ were annotated using the GlycoWorkbench software program (version: 2.1). Relative intensity was analyzed and generated using FlexAnalysis software (Bruker Daltonics, version:3.3). Coefficient of variation (CV) percentages based on relative intensity values were used to estimate the stability of mass spectrometry. Total sum quantitative of the sialylated $\mathrm{N}$-glycans $\left(S_{i}\right)$ were calculated by the equation:

$$
\begin{aligned}
S_{i}= & S_{i j} \times N_{i j}+S_{i(j+1)} \times N_{i(j+1)}+\ldots+S_{i(j+n)} \\
& \times N_{i(j+n)}
\end{aligned}
$$

with $S_{i j}=$ relative intensity of $\mathrm{N}$-glycan $\mathrm{j}$ in $\mathrm{i}$ cells, and $N_{i j}=$ number of sialic acids of $\mathrm{N}$-glycan $\mathrm{j}$ in i cells [32].

\section{FN-integrin a5 $\beta 1$ binding assay in vitro}

Purified FN were dissolved in PBS to $50 \mu \mathrm{g} / \mathrm{mL}$ and coated on to ELISA plates $\left(5 \mu \mathrm{g} / \mathrm{cm}^{2}\right)$ overnight at $4{ }^{\circ} \mathrm{C}$. The plates were washed with PBS and blocked with $3 \%$ BSA $(\mathrm{m} / \mathrm{v}$, in PBS).

Sialic acids on FN were removed by adding $1 \mathrm{U} / \mathrm{mL}$ sialidase and incubating at $37^{\circ} \mathrm{C}$ for $30 \mathrm{~min}$. After washing three times with $\mathrm{PBS}$, the plates were incubated with integrin $\alpha 5 \beta 1(20 \mu \mathrm{g} / \mathrm{mL}$, in PBST with $0.5 \%$ BSA) for $12 \mathrm{~h}$ at $4{ }^{\circ} \mathrm{C}$ with gentle shaking. After washing three times with PBST, the integrin $\alpha 5 \beta 1$ binding ratio can be detected with HRP conjugated integrin $\beta 1$ antibody (1: 1000) and TMB-ELISA Substrate Solution.

\section{Tumor formation in mice}

Animal experiments were performed in accordance with the Animal Care and Use Committee guidelines of Jiangnan University. YTS-1/Ctrl and YTS-1/NEU1 cells were suspended in RPMI-1640 medium without FBS at a density of $1 \times 10^{7}$ cells $/ \mathrm{mL}$, and $0.2 \mathrm{~mL}$ aliquots were transplanted subcutaneously into 8-week-old male BALB/c-nu mice. Tumor size was measured every other day for 21 days. At the end of 3 weeks, tumors were excised and weighed.

\section{Statistical analysis}

All values were presented as mean \pm SD from three independent experiments unless otherwise specified. Differences between means were analyzed by Student's t-test.

\section{Results}

Sialoglycans are highly expressed in bladder cancer cells Sialylated N-glycans from five bladder cancer cell lines (see Methods in Supplementary Information) were derivatized using isotope tags and analyzed. Eleven sialylated N-glycans were observed as a doublet with a 6-Da difference. The identified derivatized sialylated glycans are described in Fig. 1a. Expression levels of sialylated N-glycans were normalized as described in the Fig. 1 legend, and the putative structures are shown in Fig. 1b. Levels of sialylated $\mathrm{N}$-glycans in normal bladder cells were generally $<1$, and were lower than levels in bladder cancer cells. Averages of the ratio of N-glycans at m/z 2580.97 (SVHUC-1: KK47: J82 = 0.67: 1: 1.06), 2598.93 (HCV29: SV-HUC-1: KK47: J82=0.82: 0.50: 1: 1.24), 2946.10 (HCV29: SV-HUC-1: KK47: J82: YTS-1 = 0.91: 0.61: 1: 2.55: 1.28), and 3311.23 (HCV29: SV-HUC-1: KK47: J82: YTS-1 =0.64: 0.98: 1: 1.63: 1.61) were significantly higher in bladder cancer cells (Table S1). Results consisted with our bladder cancer tissue sialic acids lectin blotting [32]. Sambucus nigra lectin (SNA, recognizing $\alpha 2,6$-linked sialic acids) and Maackia amurensis lectin (MAL-II, recognizing $\alpha 2,3$-linked sialic acids) were used to detect sialic acids level on tissue protein of clinic bladder cancer patients. Sialic acids were significantly rich in tumor tissue sample compared to tumor adjacent tissues (Fig. 1c, Table. S2). Indicating that, accumulated sialic acids modification existed in bladder cancer cells.

\section{Downregulation of NEU1 is responsible for aberrant expression of sialoglycans}

In mammalian cells, sialyltransferases and sialidases are responsible (respectively) for addition and removal of sialic acids on glycans. We evaluated total sialidase activities of HCV29, KK47, YTS-1, and T24 cells using 4-MU-NANA as substrate. Sialidase activity was highest for normal bladder cell line HCV29, and significantly lower for bladder cancer cell lines KK47, YTS-1, and T24 (Fig. 2a).

Proteome levels of SILAC-labeled HCV29, KK47, and YTS-1 cells were quantitatively analyzed in our previous study [36]. Among the known 20 sialyltransferases and 4 sialidases, a differential signal among these three cell lines was observed only for sialidase NEU1. HR LC-MS/ MS analysis showed that higher expression of NEU1 in HCV29, and lower expression in KK47 and YTS-1 (Fig. 2b, Fig. S1). Quantitative real-time PCR and Western blotting similarly showed lower expression of NEU1 in KK47, J82, YTS-1, and T24 than in HCV29, at both mRNA (Fig. S2) and protein levels (Fig. 2c). 


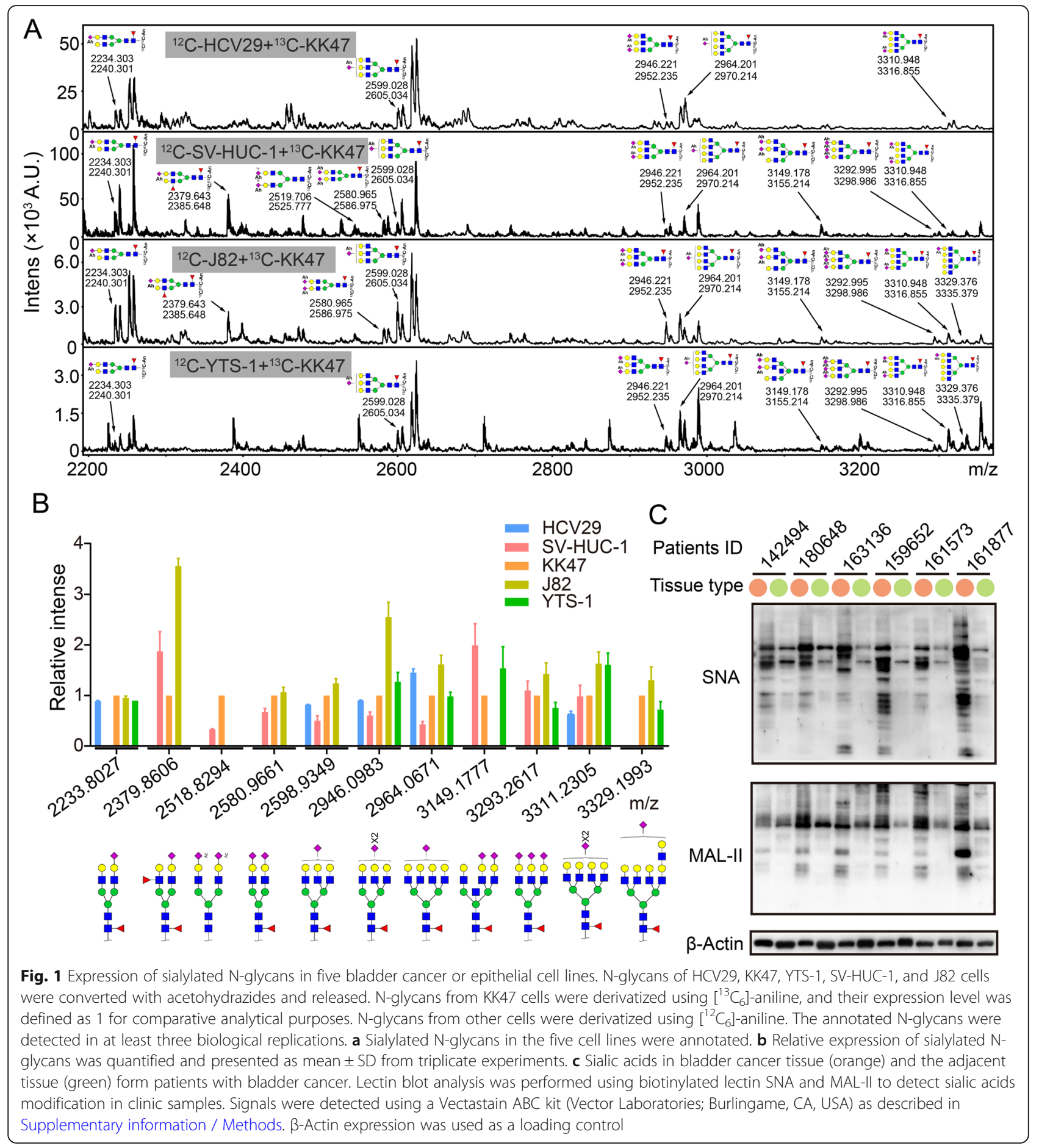

Fluorescence staining analysis revealed the same trend. Cells were stained separately with Cy3-labeled SNA and MAL-II lectins. SNA and MAL-II binding capacities were significantly higher for KK47, J82, YTS-1, and T24 than for HCV29 (Fig. 2d). In contrast to sialic acid expression, NEU1 expression was higher for HCV29 than for the four cancer cell lines (Fig. 2d). Taken together, these findings suggest that downregulated expression of NEU1 is responsible for the aberrant expression of sialic acids in bladder cancer, and is associated with bladder tumor progression.

\section{Downregulation of NEU1 and upregulation of sialic acid during EMT}

EMT, a crucial step in tumor invasion and metastasis, is a process whereby epithelial cells acquire high migratory and invasive capability, escape from the primary basement 


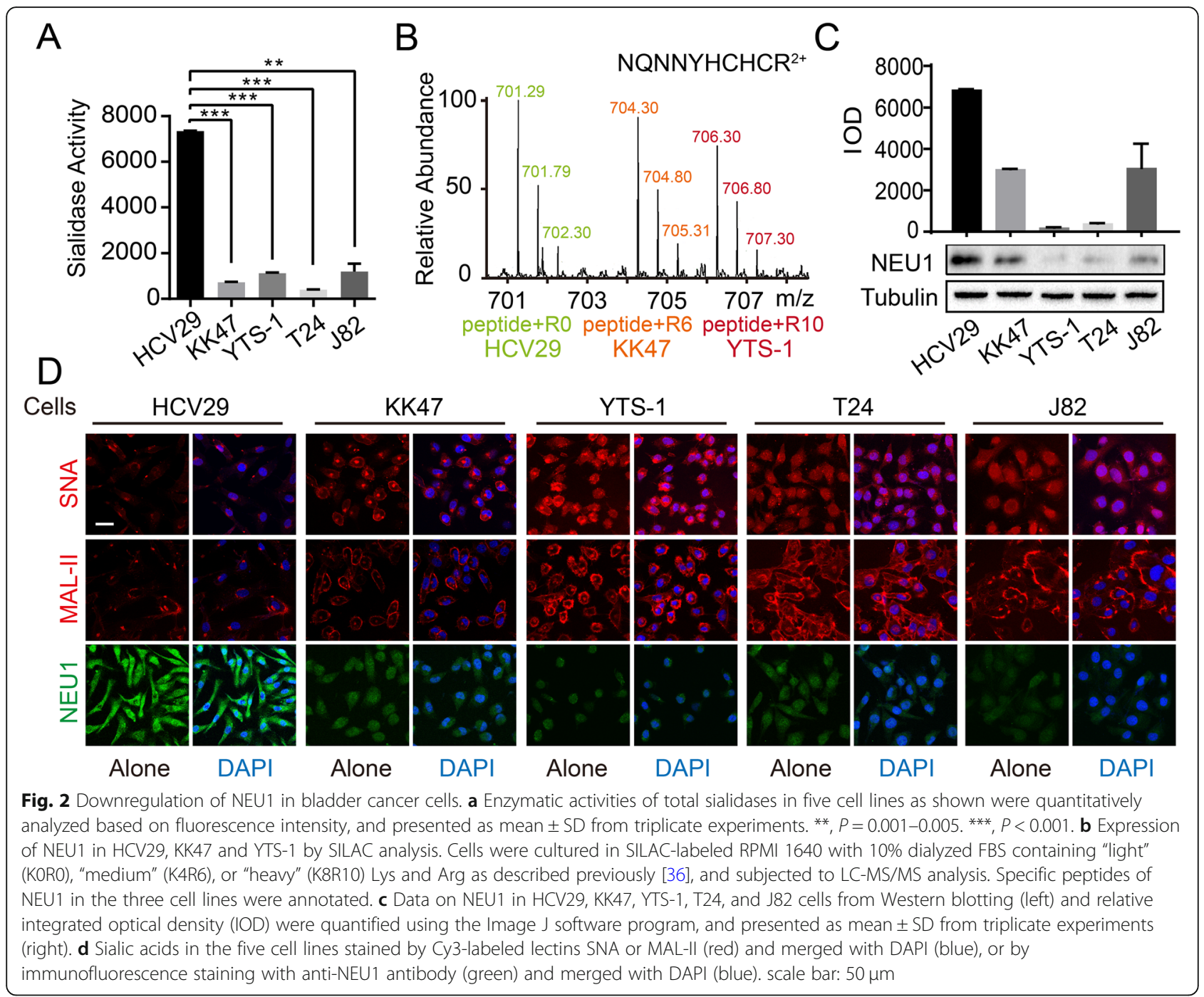

membrane to which they are normally attached, and migrate to distant sites [37]. Following TGF $\beta$ treatment, HCV29, KK47, and J82 cells showed increased levels of the typical mesenchymal markers $\mathrm{FN}$ and $\mathrm{N}$-cadherin (Fig. 3a), and enhancement of cell motility (Fig. S3). As enzymatic activities of total sialidases decreased (Fig. 3b), surface sialylation of HCV29, KK47, and J82 (recognized by lectin MAL-II and SNA) increased (Fig. 3d). Downregulation of NEU1, observed at the protein and mRNA levels (Fig. 3a, c, d), was primarily responsible for the upregulation of sialic acid during EMT.

\section{NEU1 overexpression decreases cell growth and increases} apoptosis

To investigate the molecular function of NEU1 in bladder cancer, we cloned the NEU1 gene, transfected it into bladder cancer cell lines YTS-1 and T24, and thus generated transfectant cell lines YTS-1/NEU1 and T24/NEU1.

Sialidase activity and sialic acid expression were downregulated in YTS-1/NEU1, as expected (Fig. S4A, S4B). Lectin blotting assay showed clearly reduced binding capacity of YTS-1/NEU1 to lectin SNA and MAL-II (Fig. 4a). YTS-1/NEU1 showed a lower proportion of spindle cells (Fig. 4b), reduced adhesion to FN, laminin, and collagen V, and increased adhesion to Matrigel (Fig. S5). These findings indicate that cell adhesion properties were affected by alteration of cell surface sialylation.

Cell growth of YTS-1/NEU1 and T24/NEU1 was significantly slower than that of YTS-1/Ctrl and T24/Ctrl (Fig. 4c). Cell cycle assay revealed that NEU1 overexpression resulted in a significant arrest in G0/G1 phase (Fig. 4d, e). Flow cytometric analysis using the apoptosis markers annexin $\mathrm{V}$ and PI showed that NEU1-overexpressing cells were also likely to undergo apoptosis. Percentages of total apoptotic cells 


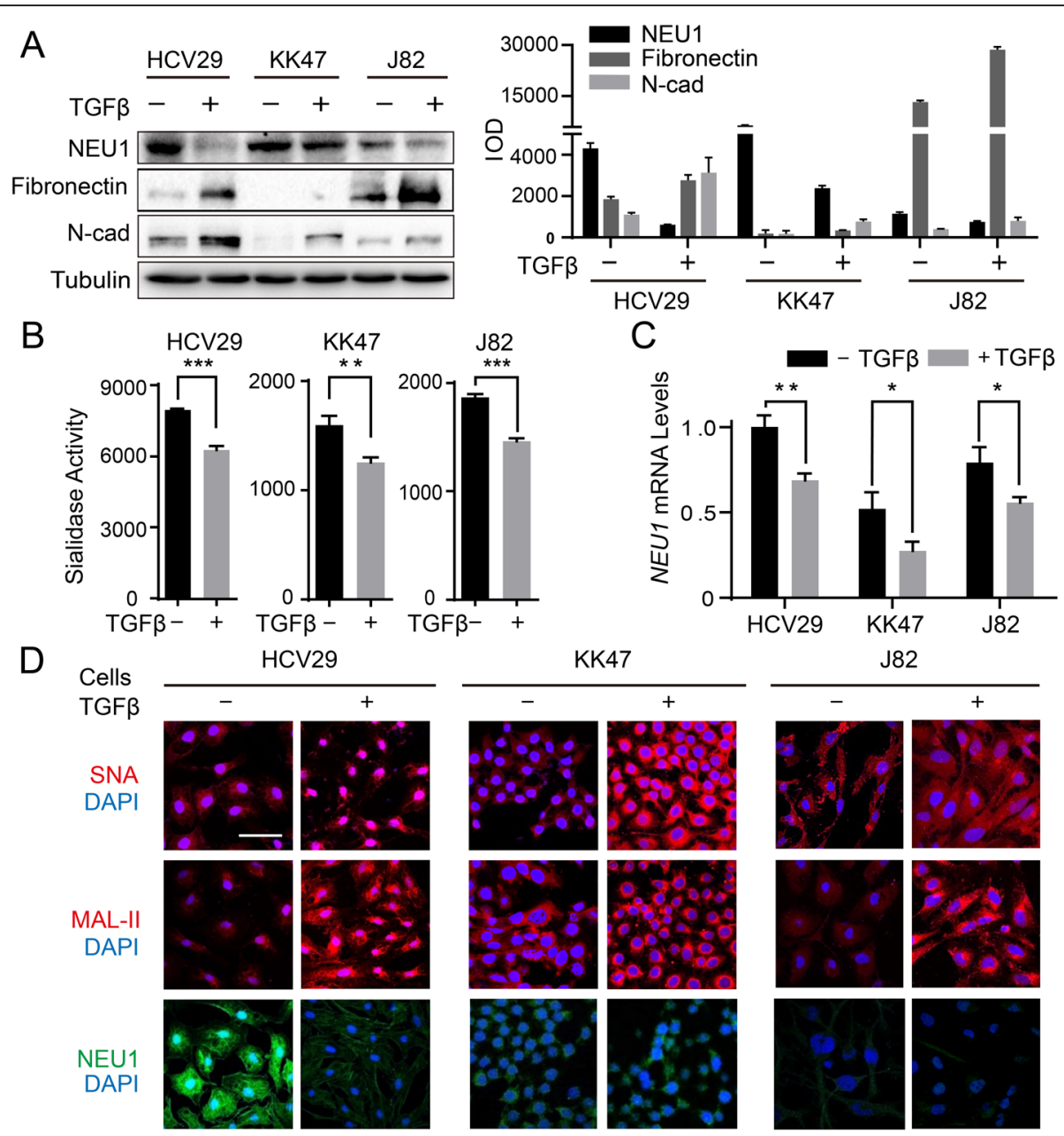

Fig. 3 Decreased expression of NEU1 during EMT. a HCV29, KK47, and J82 cells were treated with $5 \mathrm{ng} / \mathrm{mL}$ TGF $\beta$ for 48 h. Total protein was extracted with RIPA buffer, subjected to SDS-PAGE, and transferred to PVDF membrane. Membranes were incubated with antibodies against NEU1, FN, and N-cadherin, incubated with appropriate HRP-conjugated secondary antibody, and proteins were revealed with Super-signal Chemiluminescence substrate kit as described in Supplementary information / Methods. $\beta$-tubulin: loading control. b Enzymatic activities of total sialidases in TGF $\beta$-treated cells as described in Fig. 2A. c Expression of NEU1 at the mRNA level in TGF $\beta$-treated and nontreated cells. $\mathbf{d}$ Sialic acids in TGF $\beta$-treated and nontreated cells were stained by Cy3-labeled SNA, MAL-II (upper, middle), or by immunofluorescence staining with antiNEU1 (lower). Scale bar: $100 \mu \mathrm{m} .{ }^{*}, P=0.01-0.05 .{ }^{* *}, P=0.001-0.005 .{ }^{* * *}, P<0.001$

were $43.3 \%$ for T24/NEU1 vs. $19.85 \%$ for T24/Ctrl, and $20.52 \%$ for YTS-1/NEU1 vs. 3.94\% for YTS-1/Ctrl (Fig. 4f). In addition, we found that cell cycle checkpoint regulators CDK2 and cyclin D1, which have been indicated to play important roles during G0/G1 cycle transition, were down-regulated, as well as the apoptosis makers such as cleaved Caspase 9 was up-regulated and antiapoptotic protein Bcl-2 was down-regulated in YTS-1/ NEU1 (Fig. 4g). In view of the findings that NEU1 overexpression decreased cell growth and increased cell apoptosis, we analyzed EMT marker protein expression in YTS-1/NEU1. NEU1-overexpressing YTS-1 cells showed no clear change of $\mathrm{N}$-cadherin or vimentin expression (Fig. S6). In striking contrast, FN expression was significantly reduced in YTS-1/NEU1 (Fig. 4h).

\section{Akt signaling pathway is downregulated by NEU1 overexpression}

FN, a high-molecular-weight glycoprotein found in extracellular matrix (ECM), binds to the membrane-spanning integrin $\alpha 5 \beta 1$ and helps mediate cell spreading and migration. Activation of $\alpha 5 \beta 1$ protects cells against apoptosis and stimulates cell growth through a phosphatidylinositol3-kinase (PI3K)/Akt-dependent pathway [38]. In view of the downregulation of FN in NEU1-overexpressing cells (Fig. 4h), we assessed expression of the $\alpha 5 \beta 1$ and Akt pathways in YTS-1/NEU1 and T24/NEU1. Expression of FN, $\alpha$, and $\beta 1$ was lower in YTS-1/NEU1 than in YTS-1/ Ctrl. Akt protein expression was similar in YTS-1/NEU1 and YTS-1/Ctrl, but Akt phosphorylation was clearly reduced in YTS-1/NEU1 (Fig. 4h). Similarly, reduced 


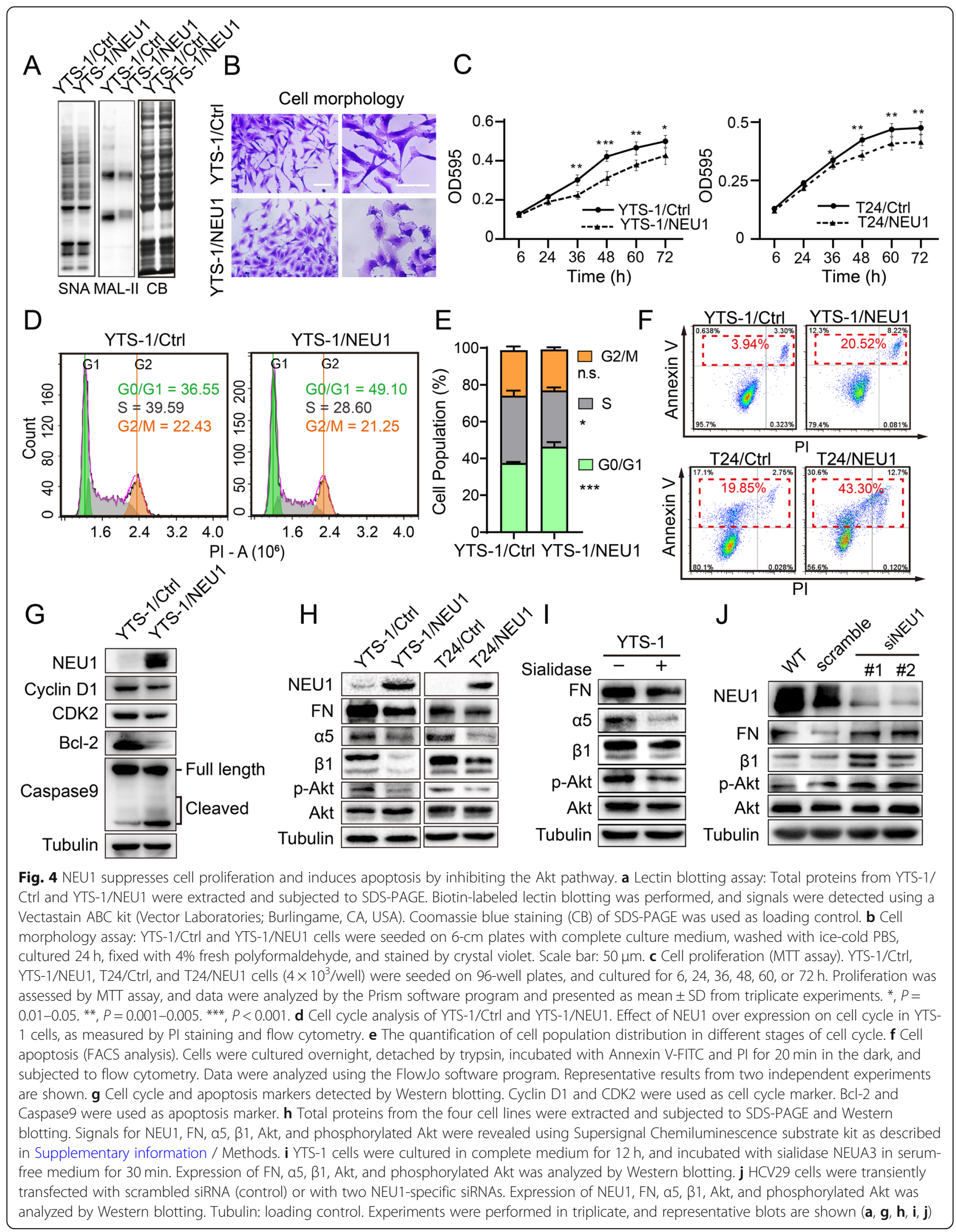


expression of FN, $\alpha 5, \beta 1$, and phosphorylated Akt was observed in T24/NEU1 relative to T24/Ctrl (Fig. 4e). We next treated YTS-1 with sialidase NeuA3, cloned from the non-pathogenic Streptomyces avermitilis and expressed in E. coli as described previously [39]. Expression of FN, $\alpha 5$, $\beta 1$, and phosphorylated Akt was clearly reduced in the NeuA3-treated cells (Fig. 4i). Oppositely, knockdown of NEU1 expression in noncancerous HCV29 cells resulted in enhanced expression of $\mathrm{FN}, \alpha 5$, and $\beta 1$, and activation of Akt pathway (Fig. 4j). Taken together, these findings indicate that NEU1 overexpression reduces cell proliferation and enhances cell apoptosis through by downregulation of FN-integrin $\beta 1$-mediated Akt signaling pathway.

\section{Alteration of $\mathrm{FN}$-integrin a $5 \beta 1$ distribution and expression by NEU1 overexpression}

NEU1 is usually localized in lysosomes, but can also be transported in extracellular vesicle or on the cell surface [17]. Assessment of NEU1 distribution showed that it was minimally expressed in YTS-1/Ctrl, but highly expressed in YTS-1/NEU1. In YTS-1/NEU1, a greater proportion of NEU1 was localized on cell membrane than in cytoplasm (Fig. 5a). Functions and downstream signaling pathways of integrin have been shown to be affected by compartmentalized expression on the cell surface. We therefore isolated proteins from plasma membrane detergent-soluble microdomain (DSM) and detergent-insoluble microdomain (DIM) fractions of YTS$1 / \mathrm{Ctrl}$ and YTS-1/NEU1, and examined the differential expression of NEU1, FN, $\alpha 5$, and $\beta 1$ in the two fractions. In YTS- $1 / C$ trl, $\alpha 5$ and $\beta 1$ were expressed primarily in DSM, and to a lesser degree in DIM. In YTS-1/NEU1, $\alpha 5$ and $\beta 1$ expression was greatly reduced overall and almost nonexistent in DIM (Fig. 5b), while overexpressed NEU1 was localized mainly in DSM. FN was detected in both DIM and DSM in YTS-1/Ctrl, but exclusively in DSM in YTS-1/NEU1 (Fig. 5b).

\section{NEU1 disrupts FN/ a5 $\beta 1$ interaction}

To examine the effect of NEU1 on FN-integrin $\alpha 5 \beta 1$ interaction, we performed co-immunoprecipitation (coIP) assay. $\beta 1$ was clearly precipitated by FN in YTS-1/ Ctrl, whereas no binding of $\beta 1$ to FN was observed in YTS-1/NEU1 (Fig. 5c). NEU1 protein was detected in FN immunoprecipitation (Fig. 5c), indicating that NEU1 is able to interact with FN. Sialylation of cell surface glycoproteins of cancer cells has been clearly shown to play an important role in malignant properties. FN has $\sim 10$ $\mathrm{N}$-linked glycosylation and O-linked glycosylation sites [40], and sialic acid is always the terminal group in elongation of $\mathrm{N}$-glycans and O-glycans. Sialylated and desialylated FN may therefore affect integrin binding and related downstream signaling. FN in YTS-1 cells was highly sialylated and the added sialidase could efficiently remove their sialic acids, the same as purified FN (Fig. 5d). FN expression is much lower in benign non-muscle-invasive bladder cancer KK47 than in YTS1. We cultured KK47 cells on control plates (no FN), or on plates coated with FN or with sialidase-treated (desialylated) FN. Expression of $\alpha 5, \beta 1$, and phosphorylated Akt was higher for cells on FN-coated plates than on control plates. In contrast, expression of these three components on desialylated-FN-coated plates was similar to that on control plates (Fig. 5e). Further, to investigate whether sialic acids on FN affected its affinity to integrin $\alpha 5 \beta 1$, an ELISA experiment was designed (Fig. $5 f$ ). Purified integrin $\alpha 5 \beta 1$ dimers showed lower binding affinity to desialylated FN, indicating that the sialic acid may change the binding ability of FN towards integrins in order to affect signal transduction.

The reduced expression of FN and $\alpha 5$ in YTS-1/NEU1 was confirmed by fluorescence microscopy (Fig. 5g). FN was clearly present in DSM of YTS-1/Ctrl, where it was co-localized with caveolin, but absent in DSM of YTS-1/ NEU1. FN - NEU1 interaction was also observed in YTS-1/NEU1. FN showed an enhanced confocal signal with lysosome-associated membrane protein 2 (LAMP2), suggesting that loss of FN in YTS-1/NEU1 may result from degradation in lysosomes (Fig. 5g).

\section{Downregulation of NEU1 expression in bladder cancer as revealed by tissue microarray (TMA) analysis}

NEU1 expression was evaluated using TMAs, including a total of 44 pairs of primary human bladder cancer tissue samples with matched adjacent noncancerous tissues (Table S3). NEU1 level was clearly higher in noncancerous bladder cells than in bladder cancer cells (Fig. 6a). In a summary of TMA analysis results, NEU1 expression was significantly lower in cancer tissue than in matched normal tissue for 40 of the 44 pairs (Fig. 6b). Survival analysis showed a significantly worse prognosis for patients with low (vs. high) NEU1 expression (Fig. 6c, Table S4). However, GEO data from 3 paired bladder cancer and adjacent normal tissues showed no significant difference of NEU1 expression at mRNA level (Fig. S7), indicating that the post-translational modification or degradation mechanism may involve in regulating NEU1 expression at protein level. The dysregulated expression of NEU1 in these clinical samples provides further evidence for a link between NEU1 expression and bladder tumor progression.

\section{NEU1 overexpression suppresses bladder tumor growth in vivo}

To assess the importance of NEU1 in tumor formation in vivo, we injected YTS-1/Ctrl or YTS-1/NEU1 cells into BALB/C-nu mice and assayed tumor growth. The YTS-1/NEU1-injected mice showed significantly slower tumor growth (Fig. 6d), and a much smaller total tumor 


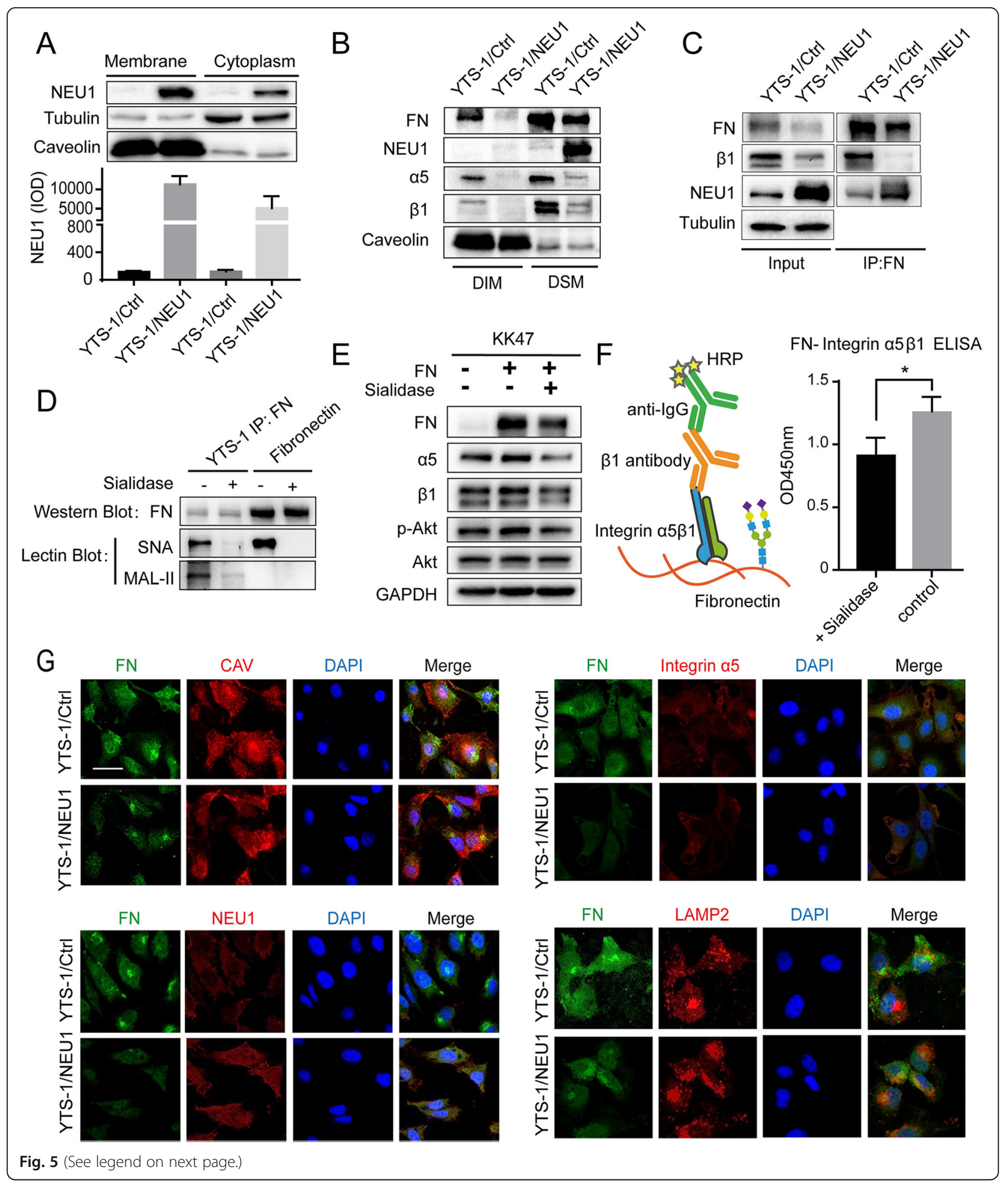




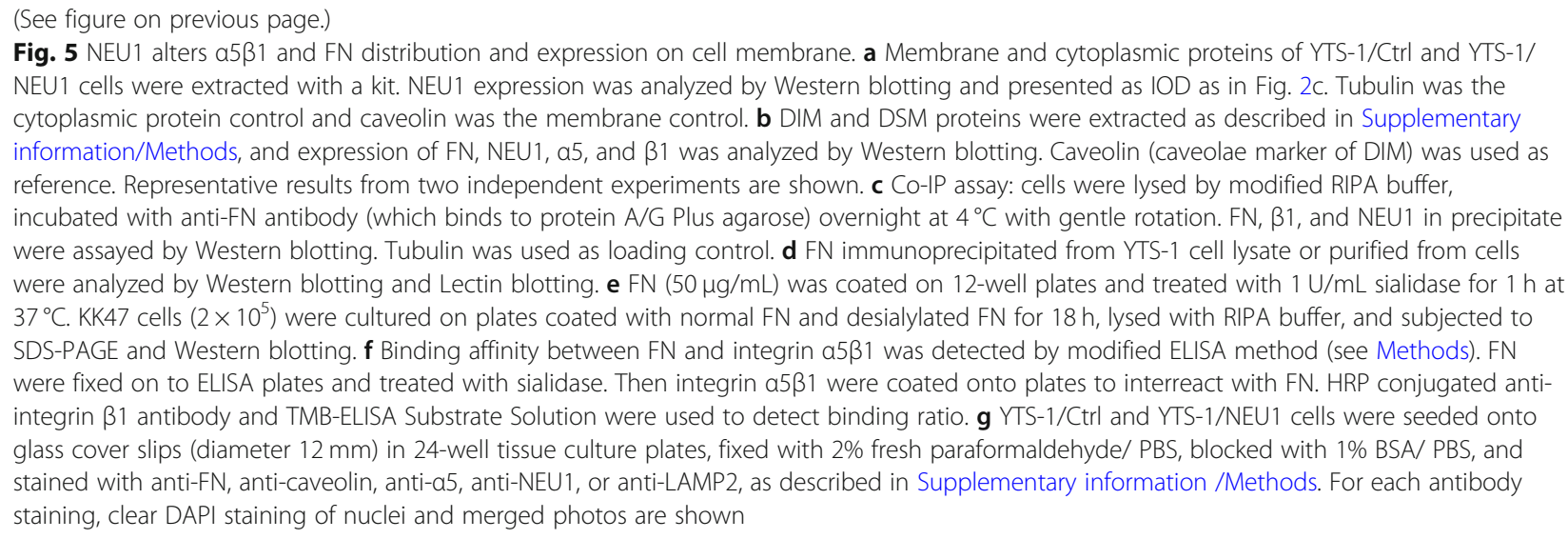

mass (Fig. 6e, f), in comparison to YTS-1/Ctrl-injected mice. In addition, immunohistochemistry of tumor tissue from BALB/c-nu mice injected with YTS-1/NEU1 cells showed significant higher NEU1 expression, lower sialic acid modification (stained by lectin SNA and MAL-II) and lower FN-integrin $\alpha 5 \beta 1$ expression, compared to the tumor from the mice injected with YTS-1/ Ctrl cells (Fig. 6g). Moreover, in tumor tissues with overexpressed NEU1, less proliferation and more apoptosis were observed (Fig. S8). These findings are consistent with those from in vitro cell proliferation assay, and indicate that NEU1 overexpression suppresses bladder tumor growth in vivo.

\section{Discussion}

During glycan synthesis, addition of sialic acid to terminal Gal or GalNAc acts as a termination signal and prevents further chain elongation. The sialylation state of glycoproteins and glycolipids is a critical factor modulating molecular recognition between adjacent cells, between cells and ECM, and between host cells and pathogens. Importantly, increased sialylation of cell surface molecules has been correlated with tumor aggressiveness [41]. Sialic acid receptor Siglec-15, which is broadly upregulated on human cancer cells, has been proved as a critical immune suppressor and as a potential target for normalization cancer immunotherapy [42]. Precise glycocalyx editing strategy which conjugated a sialidase to therapeutic monoclonal antibody trastuzumab cleaved the sialic acids on the cell surface and greatly increased tumor cell killing [43]. Sialylation state can be modified synergistically by sialyltransferases and sialidases, and there is considerable evidence for a role of aberrant sialyltransferase expression in cancer progression. However, far fewer studies have addressed the role of the four known sialidases in cancer progression.

As is known that NEU1 is a major endogenous sialidase that forms a high-molecular-weight multienzyme complex with protective protein/cathepsin A (PPCA) and the hydrolase $\beta$-galactosidase to protect them against rapid proteolytic degradation and facilitate their correct folding in lysosomes [44]. Interestingly, NEU1 was recently shown to be transported in vesicles and on the cell surface, and to perform on-site hydrolysis [45].

Published data on expression and function of NEU1 in various types of cancer appear somewhat contradictory. In human colon cancer, NEU1 expression was negatively correlated with metastasis [27]. In pancreatic cancer, enhanced NEU1 expression was involved in MMP9-EGFR signaling, and promoted cancer progression and metastasis [46]. In ovarian cancer, NEU1 siRNA inhibited cell proliferation, apoptosis, and invasion [47]. In the present study, downregulation of NEU1 was observed in bladder cancer cells and clinical samples, and NEU1 overexpression resulted in inhibition of proliferation, promotion of apoptosis, and inactivation of the Akt signaling pathway.

It is noteworthy here, that FN-integrin mediated signaling pathways, particularly the Akt pathway, have been well studied in numerous cell models $[48,49]$. NEU1 has been shown to be associated with multiple receptor signaling complexes, including TOLL-like receptor [50] and growth factors PDGF-BB and IGF-2 [51]. In human airway epithelial cells, NEU1 was associated with substrates EGFR and MUC1, and regulated ligand-dependent EGFR autophosphorylation [52, 53]. Interestingly, we observed reduced levels of FN, $\alpha 5$, and $\beta 1$ in both T24/NEU1 and YTS-1/ NEU1. Present and previous observations, taken together, strongly indicate that overexpressed NEU1 inhibits the Akt pathway by disrupting FN-integrin $\alpha 5 \beta 1$ interaction.

Herein, we proposed that sialylation promotes the tight interaction $\mathrm{FN}$-integrin $\alpha 5 \beta 1$, while de-sialylation reduces their binding capacity, and sialylation may further affect endocytosis/ recycling of FN and integrin (Fig. 7). Effects of altered sialylation of cell surface glycoproteins on malignant properties have been reported by many groups. Hypersialylation of $\beta 1$ was shown to promote tumor progression by increasing adhesion to $\mathrm{FN}$, collagen I, and certain ECM components in colonic 


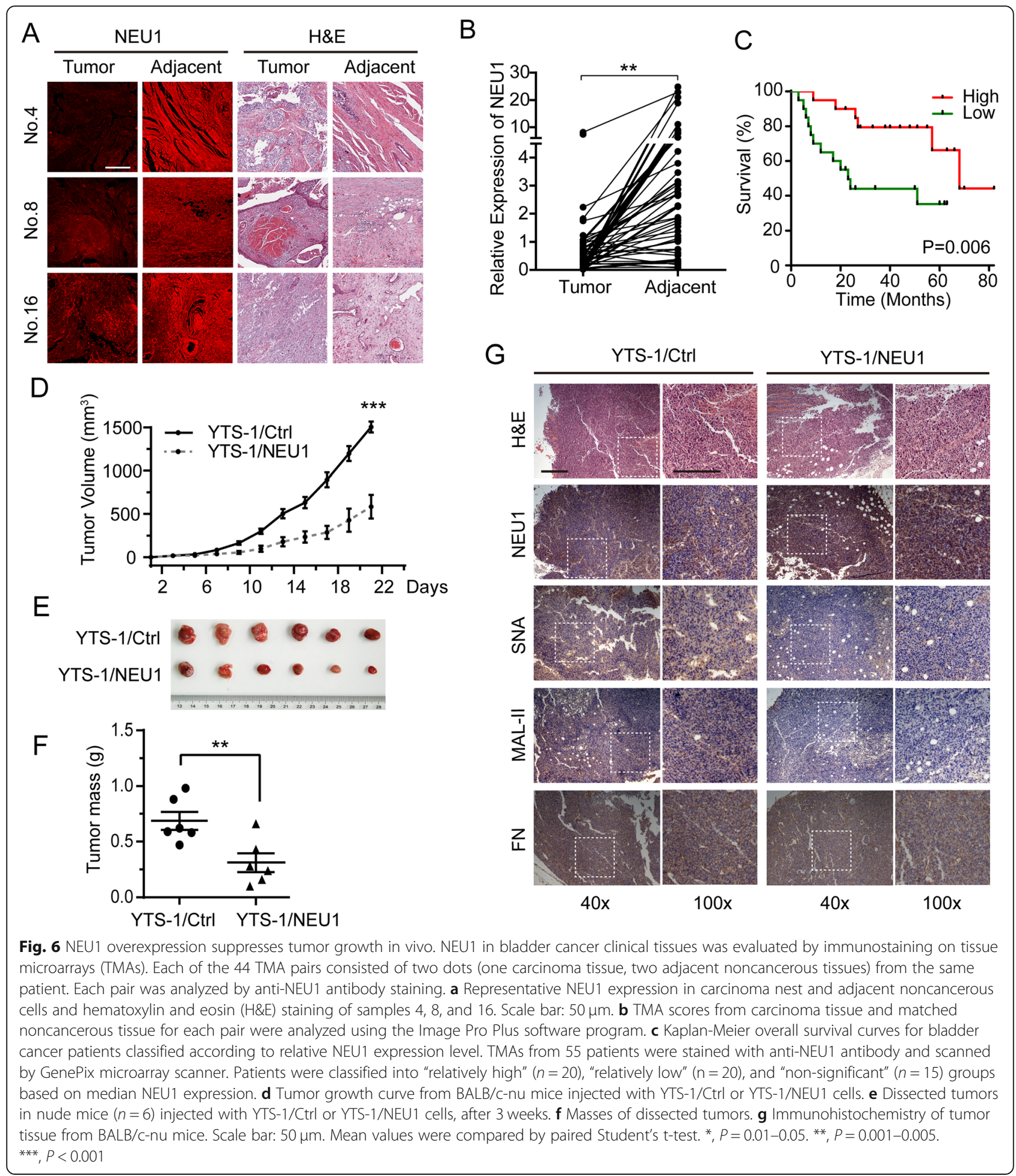

adenocarcinoma [54] and human astrocytoma cells [55]. In contrast, removal of sialic acid from integrin Oglycans resulted in decreased integrin phosphorylation and inhibition of focal adhesion kinase (FAK) and ERK1/2 pathways $[27,56]$. Sialylation of vitronectin, another ECM molecule, played a crucial role in activation of hepatic stellate cells during the liver regeneration process [57]. Although 10 N-linked and O-linked glycosylation sites on FN have been identified, little is known regarding the effects of altered glycosylation on FN $[40,58]$. It is important to elucidate the expression and function of sialylation on FN. We observed that NEU1 


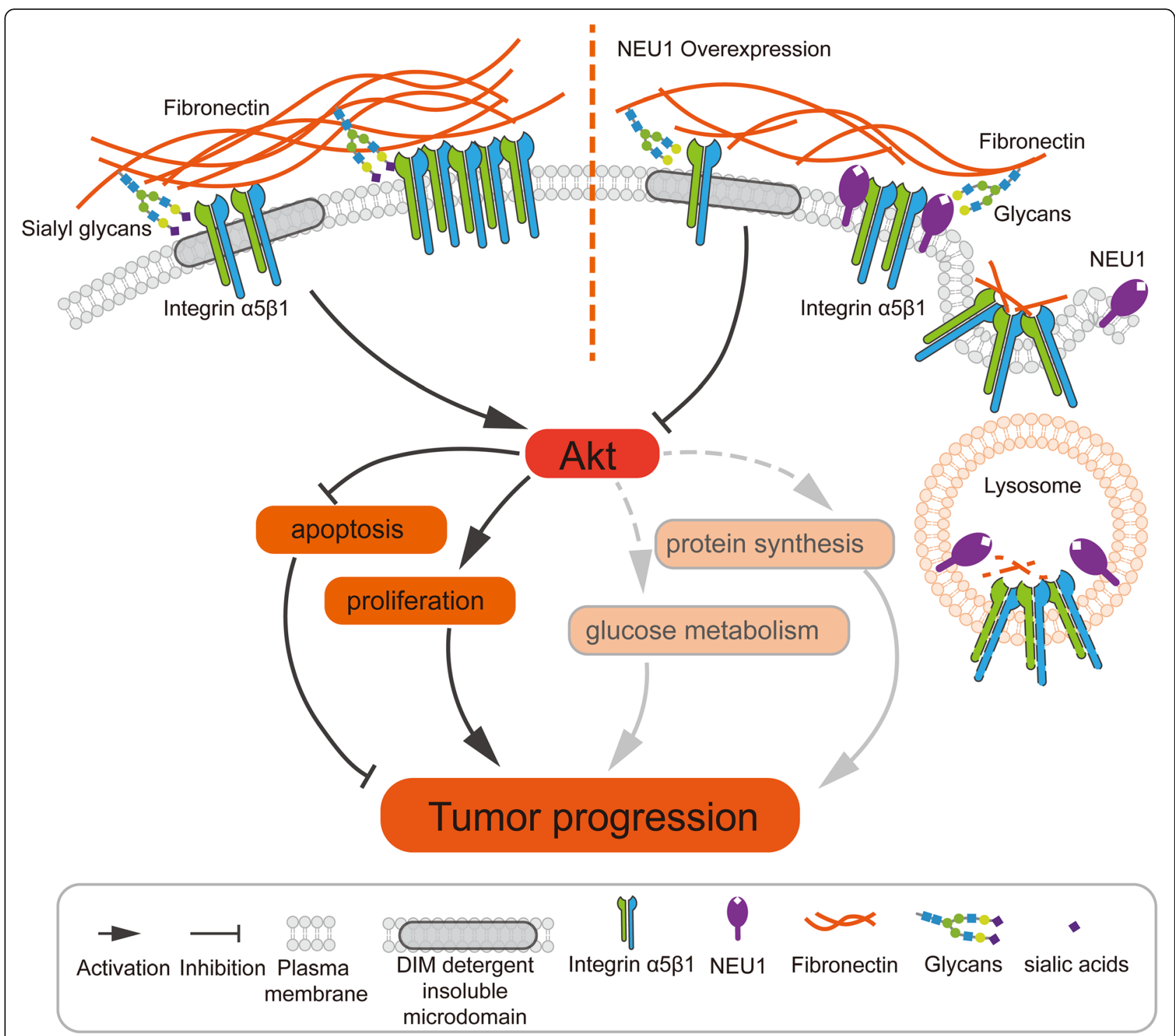

Fig. 7 Model for NEU1 disrupting fibronectin-a5ß1 interaction and inhibiting the Akt signaling pathway

was distributed predominantly in the DSM area of the cell surface, and attracted FN to this area. NEU1 overexpression altered compartmental distribution of FN and integrin, and may disrupt their interaction. On the other hand, it is noted that glycosylation could affect endocytosis of membrane glycoproteins. Endocytosis of $\beta 1$ plays an important role in matrix FN turnover, and $\beta 1$ and FN appear to be trafficking together during endocytosis [59]. Following endocytosis, FN is trafficked and degraded by lysosomes [60]. Endocytosis of bisecting GlcNAc-modified EGFR and downstream ERK phosphorylation were both enhanced in $\mathrm{N}$-acetylglucosaminyltransferase III (GnTIII)-overexpressing cells [61]. Sialylation of membrane glycoproteins is responsible for their intracellular accumulation and trafficking in some cases [62]. Lifespan and abundance of secreted proteins (mostly glycoproteins) depend on differentially exposed $\mathrm{N}$-glycan structures, for which intrinsic NEU1 and other glycosidases provide useful models [63]. Overall sialylation state on the surface of NEU1-overexpressing cells was reduced in the present study. NEU1 overexpression also decreased FN and integrin $\beta 1$ level of the plasma membrane, increased FN degradation by lysosomes, and consequently inhibited the downstream AKT pathway. This model is consistent with the observed effect of sialylation on endocytosis/ recycling of FN and integrin in bladder cancer cells. In accordance with our data, the decreased sialylation status may loose the interaction of FN and integrin $\alpha 5 \beta 1$ and further result in their endocytosis/ recycling. Therefore, a combined strategy involving experimental, computational, and structural biological approaches will help us evaluate the models described above. 


\section{Conclusions}

In conclusion, our observations indicate that NEU1 is an important modulator of the malignant properties of bladder cancer cells; i.e., NEU1 inhibited cancer cell proliferation, induced apoptosis, and suppressed tumor formation both in vitro and in vivo. NEU1 appeared to deactivate the Akt signaling pathway by disrupting FN-integrin $\alpha 5 \beta 1$ interaction. NEU1 is a potential therapeutic target for prognosis and treatment of bladder cancer. The detailed molecular mechanisms underlying the effects of NEU1 will be addressed in our subsequent study.

\section{Supplementary information}

Supplementary information accompanies this paper at https://doi.org/10. 1186/s12964-019-0500-x.

Additional file 1. Supplementary information/Methods. (Cell lines and cell culture; Antibodies and reagents; Derivatization and separation of Nglycans; Derivatization and separation of N-glycans; Stable isotope labeling by amino acids in cell culture (SILAC); Semi-quantitative and quantitative real-time RT-PCR analysis; Cell transfection; NEU1 gene silencing (siRNA); Proliferation (MTT) assay; Western blotting; Lectin blotting; Immunofluorescence staining; Immunohistochemistry; Wound assay for motility; Cell adhesion assay; Determination of apoptosis by flow cytometry; Tissue microarray (TMA) analysis; Co-immunoprecipitation (CO-IP); Extraction of detergent-soluble microdomain (DSM) and detergent-insoluble microdomain (DIM) fractions; TUNEL assay; Cell cycle assay). Table S1. Annotation and quantitative analysis by MALDI-TOF/TOF-MS of N-linked glycan. Table S2. Patient information for sialic acid lectin blot. Table S3. Patient information for analysis of NEU1 expression in tumor and adjacent tissues. Table S4. Patient information for survival analysis. Fig. S1. The intensity of NEU1 protein in LC-MS/MS analysis. Fig. S2. NEU1 mRNA expression in five bladder cancer or epithelial cell lines. Fig. S3. Cell motility during EMT. Fig. S4. Sialidase activity and sialic acid expression in NEU1-overexpressing cells. Fig. S5. Adhesion capacity of YTS-1/Ctrl and YTS-1/NEU1 cells. Fig. S6. EMT marker proteins in YTS-1/Ctrl and YTS-1/ NEU1 cells. Fig. S7. NEU1 mRNA level in bladder cancer tissue. Fig. S8. Ki67 and TUNEL staining of mice tumor tissue.

\section{Abbreviations}

4-MU-NANA: 2'-(4-methylumbelliferyl) -a-D-N-acetylneuraminic acid sodium BSA: Bovine serum albumin; CDK2: Cyclin-dependent kinases 2; co-IP: coimmunoprecipitation; CV: Coefficient of variation; DIM: Detergent-insoluble microdomain; DMSO: Dimethyl sulphoxide.; DSM: Detergent-soluble microdomain; ECM: Extracellular matrix; EGFR: Epidermal growth factor receptor; ELISA: Enzyme-linked immunosorbent assay; EMT: Epithelialmesenchymal transition; FBS: Fetal bovine serum; FN: Fibronectin; GnT-III: N acetylglucosaminyltransferase III; HCV29: Normal bladder epithelia; HR LCMS: High resolution liquid chromatography mass spectrometry; HRP: Horse radish peroxidase; J82: Transitional carcinoma urinary bladder; KK47: Benign non-muscle-invasive bladder cancer; LAMP2: Lysosome-associated membrane protein 2; MALDI-TOF: Matrix-Assisted Laser Desorption/ Ionization Time of Flight Mass Spectrometry; MAL-II: Maackia amurensis lectin, recognizing a2,3-linked sialic acids; MMP9: Matrix metalloprotein; MS: Mass spectrometry; NEU1: Sialidase-1 (neuraminidase 1); Neu5Ac: Nacetylneuraminic acid; Neu5Gc: N-glycolylneuraminic acid; PBS: Phosphate buffered saline; PI3K: Phosphatidylinositol-3-kinase; PPCA: Protective protein/ cathepsin A; RT-PCR: Quantitative real-time polymerase chain reaction; SILAC: Stable isotope labeling by amino acids in cell culture; siRNA: Small interfering RNA; SNA: Sambucus nigra lectin, recognizing a2,6-linked sialic acids; ST6GAL1: $\beta$-galactoside a-2,6-sialyltransferase 1; ST8SIA2: a-2,8sialyltransferase 2; SV-HUC-1: Human uroepithelial cell line; T24: Transitional cancers of human urine bladder; TGF $\beta$ : Transforming growth factor $\beta$; TMA: Tissue microarray; YTS-1: Highly malignant invasive bladder cancer

\section{Acknowledgements}

The authors are grateful to Dr. S. Anderson for English editing of the manuscript.

\section{Authors'contributions}

$F G$ and $X L$ designed the study. $X Z, Y Z, J G, C L$ and $G Y$ performed the experiments. $X Z, G L, C S$ and $X Q$ performed the statistical analysis. $X Z, Y Z$ and $C L$ performed the tumor formation experiments. $F G$ and $X L$ discussed the results and wrote the manuscript. All authors read and approved the final manuscript.

\section{Funding}

This study was supported by the National Science Foundation of China (No. 31971211, 81672537), National Science and Technology Major Project of China (No. 2018ZX10302205), Natural Science Foundation of Shaanxi Province, China (2019JZ-22), Youth Innovation Team of Shaanxi Universities and Natural Science Foundation of the Jiangsu Higher Education Institutions of China (No. 18KJB180001).

\section{Availability of data and materials}

The materials and datasets used during the study are available from the corresponding author on reasonable request. This article contains

Supplementary Information online.

\section{Ethics approval and consent to participate}

Bladder tissue microarray were provided by National Engineering Center for Biochip (Shanghai, China). The acquisition and use of clinic samples are under permission of Medical Ethics Committee of Jiangnan University. Tissue samples from bladder cancer patient were acquired by operation during surgical treatment and provided informed consent. Animal experiments were approved and monitored by the Animal Ethics Committee of Jiangnan University. All animal experiments were performed under ARRIVE (Animal Research: Reporting of in vivo Experiments) guidelines.

\section{Consent for publication}

Not applicable.

\section{Competing interests}

The authors declare that they have no competing interest.

\section{Author details}

${ }^{1}$ The Key Laboratory of Carbohydrate Chemistry and Biotechnology, Ministry of Education, School of Biotechnology, Jiangnan University, Wuxi, China. ${ }^{2}$ Department of Urology, Affiliated Hospital of Jiangnan University, Wuxi, China. ${ }^{3}$ Department of Pathology, Affiliated Hospital of Jiangnan University, Wuxi, China. ${ }^{4}$ Provincial Key Laboratory of Biotechnology, Joint International Research Laboratory of Glycobiology and Medicinal Chemistry, College of Life Science, Northwest University, Xi'an, China.

Received: 29 October 2019 Accepted: 16 December 2019 Published online: 12 March 2020

\section{References}

1. Varki A. Glycan-based interactions involving vertebrate sialic-acidrecognizing proteins. Nature. 2007:446:1023-9.

2. Schnaar RL, Gerardy-Schahn R, Hildebrandt H. Sialic acids in the brain: gangliosides and polysialic acid in nervous system development, stability, disease, and regeneration. Physiol Rev. 2014;94:461-518.

3. Schauer R, Kamerling JP. Exploration of the Sialic acid world. Adv Carbohydr Chem Biochem. 2018;75:1-213.

4. Crocker PR. Siglecs: sialic-acid-binding immunoglobulin-like lectins in cellcell interactions and signalling. Curr Opin Struct Biol. 2002;12:609-15.

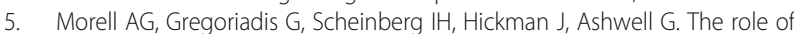
sialic acid in determining the survival of glycoproteins in the circulation. J Biol Chem. 1971;246:1461-7.

6. Schauer R. Sialic acids as antigenic determinants of complex carbohydrates. Adv Exp Med Biol. 1988;228:47-72.

7. Liu N, Zhu M, Linhai Y, Song Y, Gui X, Tan G, et al. Increasing HER2 alpha2,6 sialylation facilitates gastric cancer progression and resistance via the Akt and ERK pathways. Oncol Rep. 2018;40:2997-3005. 
8. Imamaki R, Ogawa K, Kizuka Y, Komi Y, Kojima S, Kotani N, et al. Glycosylation controls cooperative PECAM-VEGFR2-beta3 integrin functions at the endothelial surface for tumor angiogenesis. Oncogene. 2018;37:4287-99.

9. Choi HJ, Chung TW, Choi HJ, Han JH, Choi JH, Kim CH, et al. Increased alpha2-6 sialylation of endometrial cells contributes to the development of endometriosis. Exp Mol Med. 2018:50:164.

10. Dusoswa SA, Horrevorts SK, Ambrosini M, Kalay H, Paauw NJ, Nieuwland R, et al. Glycan modification of glioblastoma-derived extracellular vesicles enhances receptor-mediated targeting of dendritic cells. J Extracell Vesicles. 2019:8:1648995.

11. Li F, Ding J. Sialylation is involved in cell fate decision during development, reprogramming and cancer progression. Protein Cell. 2019;10:550-65.

12. Muhammad N, Bhattacharya S, Steele R, Phillips N, Ray RB. Involvement of c-Fos in the promotion of Cancer stem-like cell properties in head and neck squamous cell carcinoma. Clin Cancer Res. 2017:23:3120-8.

13. Feng R, Morine $Y$, Ikemoto T, Imura S, Iwahashi S, Saito Y, et al. Nrf2 activation drive macrophages polarization and cancer cell epithelialmesenchymal transition during interaction. Cell Commun Signal. 2018;16:54.

14. Hong W, Zhang G, Lu H, Guo Y, Zheng S, Zhu H, et al. Epithelial and interstitial Notch1 activity contributes to the myofibroblastic phenotype and fibrosis. Cell Commun Signal. 2019:17:145

15. Brabletz T, Kalluri R, Nieto MA, Weinberg RA. EMT in cancer. Nat Rev Cancer. 2018;18:128-34

16. Narayanan S. Sialic acid as a tumor marker. Ann Clin Lab Sci. 1994;24:376-84.

17. Pearce OM, Laubli H. Sialic acids in cancer biology and immunity. Glycobiology. 2016;26:111-28.

18. Vajaria BN, Patel PS. Glycosylation: a hallmark of cancer? Glycoconj J. 2017; 34:147-56

19. Palaniappan KK, Bertozzi CR. Chemical Glycoproteomics. Chem Rev. 2016; 116:14277-306

20. Dall'Olio F, Chiricolo M. Sialyltransferases in cancer. Glycoconj J. 2001;18: $841-50$

21. Zhao Y, Li Y, Ma H, Dong W, Zhou H, Song $X$, et al. Modification of sialylation mediates the invasive properties and chemosensitivity of human hepatocellular carcinoma. Mol Cell Proteomics. 2014;13:520-36.

22. Lu J, Isaji T, Im S, Fukuda T, Hashii N, Takakura D, et al. beta-Galactoside alpha2,6-sialyltranferase 1 promotes transforming growth factor-beta-mediated epithelial-mesenchymal transition. J Biol Chem. 2014;289:34627-41.

23. Falconer RA, Errington RJ, Shnyder SD, Smith PJ, Patterson LH. Polysialyltransferase: a new target in metastatic cancer. Curr Cancer Drug Targets. 2012;12:925-39.

24. Kakugawa Y, Wada T, Yamaguchi K, Yamanami H, Ouchi K, Sato I, et al. Upregulation of plasma membrane-associated ganglioside sialidase (Neu3) in human colon cancer and its involvement in apoptosis suppression. Proc Natl Acad Sci U S A. 2002;99:10718-23.

25. Ueno S, Saito S, Wada T, Yamaguchi K, Satoh M, Arai Y, et al. Plasma membrane-associated sialidase is up-regulated in renal cell carcinoma and promotes interleukin-6-induced apoptosis suppression and cell motility. J Biol Chem. 2006:281:7756-64.

26. Yoshinaga A, Kajiya N, Oishi K, Kamada Y, Ikeda A, Chigwechokha PK, et al. NEU3 inhibitory effect of naringin suppresses cancer cell growth by attenuation of EGFR signaling through GM3 ganglioside accumulation. Eur J Pharmacol. 2016;782:21-9.

27. Uemura T, Shiozaki K, Yamaguchi K, Miyazaki S, Satomi S, Kato K, et al. Contribution of sialidase NEU1 to suppression of metastasis of human colon cancer cells through desialylation of integrin beta4. Oncogene. 2009;28:1218-29.

28. Lee C, Liu A, Miranda-Ribera A, Hyun SW, Lillehoj EP, Cross AS, et al. NEU1 sialidase regulates the sialylation state of $\mathrm{CD} 31$ and disrupts $\mathrm{CD} 31$-driven capillary-like tube formation in human lung microvascular endothelia. J Biol Chem. 2014;289:9121-35.

29. Siegel RL, Miller KD, Jemal A. Cancer statistics, 2019. CA Cancer J Clin. 2019; 69:7-34.

30. Bray F, Ferlay J, Soerjomataram I, Siegel RL, Torre LA, Jemal A. Global cancer statistics 2018: GLOBOCAN estimates of incidence and mortality worldwide for 36 cancers in 185 countries. CA Cancer J Clin. 2018;68:394-424.

31. Ferlay J, Colombet M, Soerjomataram I, Mathers C, Parkin DM, Pineros M, et al. Estimating the global cancer incidence and mortality in 2018: GLOBOCAN sources and methods. Int J Cancer. 2019;144:1941-53.

32. Yang G, Tan Z, Lu W, Guo J, Yu H, Yu J, et al. Quantitative glycome analysis of $\mathrm{N}$-glycan patterns in bladder cancer vs normal bladder cells using an integrated strategy. J Proteome Res. 2015;14:639-53.
33. Satoh M, Ito A, Nojiri H, Handa K, Numahata K, Ohyama C, et al. Enhanced GM3 expression, associated with decreased invasiveness, is induced by brefeldin a in bladder cancer cells. Int J Oncol. 2001;19:723-31.

34. Potier M, Mameli L, Belisle M, Dallaire L, Melancon SB. Fluorometric assay of neuraminidase with a sodium (4-methylumbelliferyl-alpha-D-Nacetylneuraminate) substrate. Anal Biochem. 1979:94:287-96.

35. Xia B, Feasley CL, Sachdev GP, Smith DF, Cummings RD. Glycan reductive isotope labeling for quantitative glycomics. Anal Biochem. 2009;387:162-70.

36. Yang G, Xu Z, Lu W, Li X, Sun C, Guo J, et al. Quantitative analysis of differential proteome expression in bladder Cancer vs. Normal Bladder Cells Using SILAC Method. PLoS One. 2015;10:e0134727.

37. Lee JM, Dedhar S, Kalluri R, Thompson EW. The epithelial-mesenchymal transition: new insights in signaling, development, and disease. J Cell Biol. 2006;172:973-81.

38. Han SW, Roman J. Fibronectin induces cell proliferation and inhibits apoptosis in human bronchial epithelial cells: pro-oncogenic effects mediated by PI3-kinase and NF-kappa B. Oncogene. 2006;25:4341-9.

39. Guo J, Wang YC, Song B, Wang X, Yang GL, Guan F. Identification and functional characterization of intracellular sialidase NeuA3 from Streptomyces avermitilis. Process Biochem. 2015;50:752-8.

40. Tajiri M, Yoshida S, Wada Y. Differential analysis of site-specific glycans on plasma and cellular fibronectins: application of a hydrophilic affinity method for glycopeptide enrichment. Glycobiology. 2005;15:1332-40.

41. Teoh ST, Ogrodzinski MP, Ross C, Hunter KW, Lunt SY. Sialic acid metabolism: a key player in breast Cancer metastasis revealed by metabolomics. Front Oncol. 2018;8:174.

42. Wang J, Sun J, Liu LN, Flies DB, Nie X, Toki M, et al. Siglec-15 as an immune suppressor and potential target for normalization cancer immunotherapy. Nat Med. 2019;25:656-66.

43. Xiao H, Woods EC, Vukojicic P, Bertozzi CR. Precision glycocalyx editing as a strategy for cancer immunotherapy. Proc Natl Acad Sci U S A. 2016;113: 10304-9.

44. Bonten EJ, Annunziata I, d'Azzo A. Lysosomal multienzyme complex: pros and cons of working together. Cell Mol Life Sci. 2014;71:2017-32.

45. Sumida M, Hane M, Yabe U, Shimoda Y, Pearce OM, Kiso M, et al. Rapid trimming of cell surface Polysialic acid (PolySia) by exovesicular Sialidase triggers release of preexisting surface Neurotrophin. J Biol Chem. 2015;290: 13202-14.

46. Gilmour AM, Abdulkhalek S, Cheng TS, Alghamdi F, Jayanth P, O'Shea LK, et al. A novel epidermal growth factor receptor-signaling platform and its targeted translation in pancreatic cancer. Cell Signal. 2013;25: 2587-603.

47. Ren LR, Zhang LP, Huang SY, Zhu YF, Li WJ, Fang SY, et al. Effects of sialidase NEU1 siRNA on proliferation, apoptosis, and invasion in human ovarian cancer. Mol Cell Biochem. 2016:411:213-9.

48. Fedorenko IV, Abel EV, Koomen JM, Fang B, Wood ER, Chen YA, et al. Fibronectin induction abrogates the BRAF inhibitor response of BRAF V600E/PTEN-null melanoma cells. Oncogene. 2016;35:1225-35.

49. Nam JM, Onodera Y, Bissell MJ, Park CC. Breast cancer cells in three-dimensional culture display an enhanced radioresponse after coordinate targeting of integrin alpha5beta1 and fibronectin. Cancer Res. 2010;70:5238-48.

50. Amith SR, Jayanth P, Franchuk S, Finlay $T$, Seyrantepe $V$, Beyaert $R$, et al. Neu1 desialylation of sialyl alpha-2,3-linked beta-galactosyl residues of TOLLlike receptor 4 is essential for receptor activation and cellular signaling. Cell Signal. 2010:22:314-24.

51. Hinek A, Bodnaruk TD, Bunda S, Wang Y, Liu K. Neuraminidase-1, a subunit of the cell surface elastin receptor, desialylates and functionally inactivates adjacent receptors interacting with the mitogenic growth factors PDGF-BB and IGF-2. Am J Pathol. 2008;173:1042-56.

52. Lillehoj EP, Hyun SW, Feng C, Zhang L, Liu A, Guang W, et al. NEU1 sialidase expressed in human airway epithelia regulates epidermal growth factor receptor (EGFR) and MUC1 protein signaling. J Biol Chem. 2012;287:8214-31.

53. Lillehoj EP, Hyun SW, Liu A, Guang W, Verceles AC, Luzina IG, et al. NEU1 Sialidase regulates membrane-tethered Mucin (MUC1) Ectodomain adhesiveness for Pseudomonas aeruginosa and decoy receptor release. J Biol Chem. 2015;290:18316-31.

54. Seales EC, Jurado GA, Brunson BA, Wakefield JK, Frost AR, Bellis SL. Hypersialylation of beta1 integrins, observed in colon adenocarcinoma, may contribute to cancer progression by up-regulating cell motility. Cancer Res. 2005;65:4645-52. 
55. Bartik P, Maglott A, Entlicher G, Vestweber D, Takeda K, Martin S, et al. Detection of a hypersialylated beta1 integrin endogenously expressed in the human astrocytoma cell line A172. Int J Oncol. 2008;32:1021-31.

56. Semel AC, Seales EC, Singhal A, Eklund EA, Colley K, Bellis SL.

Hyposialylation of integrins stimulates the activity of myeloid fibronectin receptors. J Biol Chem. 2002;277:32830-6.

57. Sano K, Miyamoto Y, Kawasaki N, Hashii N, Itoh S, Murase M, et al. Survival signals of hepatic stellate cells in liver regeneration are regulated by glycosylation changes in rat vitronectin, especially decreased sialylation. J Biol Chem. 2010;285:17301-9.

58. Freire-de-Lima L, Gelfenbeyn K, Ding Y, Mandel U, Clausen H, Handa K, et al, Involvement of O-glycosylation defining oncofetal fibronectin in epithelialmesenchymal transition process. Proc Natl Acad Sci U S A. 2011;108:17690-5.

59. Lobert VH, Brech A, Pedersen NM, Wesche J, Oppelt A, Malerod L, et al. Ubiquitination of alpha 5 beta 1 integrin controls fibroblast migration through lysosomal degradation of fibronectin-integrin complexes. Dev Cell. 2010;19:148-59.

60. Sottile J, Chandler J. Fibronectin matrix turnover occurs through a caveolin1-dependent process. Mol Biol Cell. 2005;16:757-68.

61. Sato Y, Takahashi M, Shibukawa Y, Jain SK, Hamaoka R, Miyagawa J, et al. Overexpression of $\mathrm{N}$-acetylglucosaminyltransferase III enhances the epidermal growth factor-induced phosphorylation of ERK in HeLaS3 cells by up-regulation of the internalization rate of the receptors. J Biol Chem. 2001; 276:11956-62.

62. Ulloa F, Real FX. Benzyl-N-acetyl-alpha-D-galactosaminide induces a storage disease-like phenotype by perturbing the endocytic pathway. J Biol Chem. 2003;278:12374-83.

63. Yang WH, Aziz PV, Heithoff DM, Mahan MJ, Smith JW, Marth JD. An intrinsic mechanism of secreted protein aging and turnover. Proc Natl Acad Sci U S A. $2015 ; 112: 13657-62$.

\section{Publisher's Note}

Springer Nature remains neutral with regard to jurisdictional claims in published maps and institutional affiliations.

Ready to submit your research? Choose BMC and benefit from:

- fast, convenient online submission

- thorough peer review by experienced researchers in your field

- rapid publication on acceptance

- support for research data, including large and complex data types

- gold Open Access which fosters wider collaboration and increased citations

- maximum visibility for your research: over $100 \mathrm{M}$ website views per year

At $\mathrm{BMC}$, research is always in progress.

Learn more biomedcentral.com/submissions 